\title{
The Lockdown of Koti Intimacies
}

\section{Banhishikha Ghosh}

\begin{abstract}
Aвstract: This article considers the way the outbreak of coronavirus and the subsequent lockdown have egregiously impeded the intimate life practices of Kotis, people who possess a distinct gender-variant identity in India. The Kotis, who subsist mostly on begging or sex work through cross-dressing, counter the hegemonic heteronormative 'bodyscape' that fetishizes bodily differences and reinforces normative intimate practices. Using narratives and documentary evidence on their lives, this article elaborates how Koti livelihoods and the intimate practices circumambient of such livelihoods are withering away because of the pandemic. Tragically today, they are branded as 'corona transmitters', and their intimate practices are stigmatised as 'infectious'. A restraint on their physical movement and gathering in public spaces due to the pandemic has ramifications not only for their livelihood, but also for their intimate practices and identity assertions.
\end{abstract}

KeYwords: bodyscape, COVID-19, gender variant identities, intimate practices, Kotis, livelihoods

The COVID-19 pandemic has greatly affected diverse sections of the Indian population, predominantly those in working-class professions. To curtail and counteract the pandemic, a nationwide lockdown was commenced on 24 March 2020. The pandemic has impacted the intimate lives of different gendervariant communities (GVCs) ${ }^{1}$ in India (including the Kotis) in inscrutable ways. Based on documentary evidence and unstructured narratives, this article considers how the alternative bodyscapes of the Koti ${ }^{2}$ community have been muffled and how their livelihoods and the intimate practices circumambient of such livelihoods are withering away because of the pandemic. It has been documented that 87 per cent of the GVCs, including the Kotis, subsist on ritual begging and sex work (Shaikh et al. 2016) and lead a peripatetic lifestyle, travelling from one part of the country to another. While many of them disengage themselves from social (heterosexual and heteronormative) institutions like marriage and family, the literature (Nanda 1990; Reddy 2005) suggests that they are a part of 'clandestine cultural families' consisting of their lovers, clients, and other Koti community members. However, the pandemic prompted new rules of social distancing which curtailed the livelihoods of a large section of Kotis, as both begging and sex work entailed a high level of public presence and physical contact. A substantial segment of the Kotis was compelled to become transient as a result of the outbreak (Panday 2020; Trivedi 2020). Subsequently, many of them have been considering transitioning to other low-paid livelihood options in order to escape from the heightened social stigma associated with their current livelihoods as a result of the pandemic within Indian society.

\section{Lockdown of Intimacies}

The strategy of lockdown, including social distancing, is now seen as a 'lockdown of intimacies' by most members of the GVCs. The intimate practices of the Kotis ask us to envisage how minority sexualities battle to subsist amidst a hegemonic 'bodyscape ${ }^{3}$ (Geller 2009) that fetishises bodily differences to reinforce (hetero)normative intimacy practices. Like all GVCs, the Kotis experience varying degrees of intimacy ${ }^{4}$ and interpersonal interactions with their 
'significant others' (Mead 1962). For the Kotis, the locus of intimacy lies outside their natal family. The idea of choosing one's own intimate circle is a powerful signifier for many sexual minority communities including the Kotis (Silva and Smart 1999). They develop their own clandestine cultural families and intimate circles consisting of members of the Koti community and parikhs (men with whom they develop romantic relationships). Kotis spend a significant amount of time in 'cruising sites', where they network with each other and meet parikhs and clients. While these sites are mostly located in public spaces such as parks or bridges, they also serve as intensely rich interactive intimate spaces, as they successfully weave a 'thread of reciprocity' making the Kotis into 'emotional communities' (Maffesoli 1996: 12). However, the pandemic disconnected the Kotis from their communities, which used to serve as important support groups for them. Neha's ${ }^{5}$ (27 years old) narrative confirms how intimate relationships play an important role in the constitution of the intimate Koti identity. She says:

I cannot frequent the cruising sites any more. I used to earn around 700 to 1,000 rupees per day from challa-mangti [ritual begging] and sex work at Hashikhushi Park at Esplanade [Kolkata, West Bengal]. I have almost no savings now. I pine to meet my Koti friends and my parikh, Sarat. Sarat was my client earlier, but now our relationship has blossomed into something more intimate. While most married couples throughout the country are quarantined together inside their homes, the COVID lockdown for us seems to be like a lockdown of our intimacies; it is like a lockdown of our right to love.

The relationships of Kotis with their parikhs are still considered 'deviant' in Indian society, and marriage between them is not socially recognised. Therefore, most Koti intimacies are cemented in cruising sites like Hashikhushi Park. The roots of Koti-parikh intimacies may originate in cruising sites through the corporeal act of intimacy (as in the case of Neha and Sarat), but such intimate associations become an important part of the Koti 'bodyscape' (Geller 2009). Koti bodyscapes, therefore, are moulded in cruising sites and they hold the capacity to transform, remodel and subvert heteronormative modes of intimacy. For Kotis, the idea of 'home' is represented by intimate people surrounding a cruising site, who serve as important support groups and provide meaning to their life. Further, for Kotis, such sites also serve as spaces where they meet their local non-governmental organisation (NGO) and civil society representatives, who come and distribute free condoms, and provide mental health counselling. Isolation from such spaces, due to the pandemic, has had pernicious effects on them. On 21 May 2020, a gender-variant individual in Mumbai committed suicide, being unable to deal with the crisis that unfolded due to the pandemic (Times of India 2020). The pandemic hit GVCs like the Kotis hard, socially isolating them, financially draining them and branding their intimate practices as 'infectious'.

\section{'Corona Transmitters': The Withering Away of Koti Livelihoods}

The pandemic has disrupted and fractured the intimate lives of the Kotis on many levels. The intense social stigma surrounding such GVCs has only increased as a result of the pandemic. Due to their professions, which involve a significant amount of physical contact, they have been branded as 'corona transmitters'. In several parts of India and particularly in the Metros, posters have been put up which label the intimate practices of different GVCs as being contagious. One such poster reads: 'If you talk to transgenders, you will get Corona' (Jose 2020; Rosario 2020). Another reads:

Warning: Do not allow Kojja, Hijras ${ }^{6}$ near the shops. If you talk to them or have sex with them, you will be infected with CoronaVirus. Beat \& drive them away or call 100 immediately. Save people from Corona Virus Hijras. (The Week 2020)

As a result of such irrational fears, many of them have been evicted from their rented accommodations as well. In some cases, they have had to reluctantly adjust with their natal families and live in 'hostile circumstances' (Trivedi 2020). Hina's (23 years old) narrative elucidates how the pandemic further obfuscated the equations she had with the significant others of her natal family. Hina used to live in a rented apartment, and subsisted on challa-mangti. One day, she heard about a local NGO providing grocery and safety kits to gender-variant people, so she decided to go and collect it. She says:

When I went to collect the food, I met Shweta and Komal, my Koti friends. We started talking; it felt so nice to finally be able to have a heartfelt conversation after so long. Komal's house was nearby, so I decided to stay there and we decided to cook together with the groceries we got. But when I came back to my apartment the next day, my neighbours started complaining to the landlord that I had gone to do sex work, and could be a probable 'corona transmitter'. I was forcefully evicted from my house. With 
nowhere else to go, I had to move and live with my parents. I felt so strangulated in my natal home with my mother, father and younger brother. My father and brother had stopped talking to me the day they came to know that I had joined the Koti community. And being stuck in home with them during COVID-19 only made things worse. Even the neighbours stopped interacting with my family members. I felt extremely ashamed of myself; so I called the NGO lady whom I knew and she arranged for my stay at the NGO office. Since the last one month, I have been staying here in a makeshift bed.

Following Kenneth Plummer's (1995) idea of intimate citizenship, it is important to note that the intimate practices of the Kotis have adverse bearings on their life chances as citizens. It is significant that many Kotis do not have government documents such as voter cards, Aadhar cards and ration cards to procure free rations from the fair price shops (Panday 2020). Further, many suffer from chronic health conditions like diabetes and AIDS, and are more prone to infections (Misra 2020). Their intimate bodies are embedded within complex structural power relations. Their intimate desires, pleasures and ways of being in the world can muffle their access to rights and privileges as citizens (Plummer 1995).

It is in such a context that some Kotis have decided to join other occupations to sustain themselves. Prerana (48 years old) was a sex worker before the pandemic. She states:

I earned around 1,500 rupees a day before. But I have been sitting at home for two months now without any income. I came to know from a friend that a housing complex is looking for a security guard. I decided to take on that job. In my new job, I cannot cross-dress. I have to clothe, act and talk like a man. The salary also is extremely low. It is still better than having nothing.

Santosh Kr. Giri, a Koti leader of a community-based organisation (CBO), ${ }^{7}$ Kolkata Rista, ${ }^{8}$ is trying to work with funding agencies to develop alternative training workshops for the Kotis. She says:

Almost all the Koti community members in major states in India I know have been left without any means of sustenance after the outbreak. Due to the fear and stigma surrounding their professions, they might not be able to resume their livelihood practices for a long time. COVID-19 is here to stay. So we are trying to develop alternative livelihoods for the Kotis to live a life of dignity, where they will not be called 'corona spreaders'.

Giri's organisation is trying to come up with online workshops on beauty training and cooking for the
Kotis, so that they can join beauty parlours as beauticians and small restaurants as cooks in the forthcoming months.

In the process of transitioning to these new occupations, however, their identity and intimate practices as gender-variant individuals get glossed over (as in the case of Prerana), and they have to work either as men or women depending on the context. Thus, it can be said that the pandemic has egregiously hindered the livelihoods of the Kotis. The effects of this have been dreadful: a cutting off from formal and informal support and an effective withering away of intimate practices of the Kotis. The result is a very suddenly disappearing world.

\section{Conclusion}

Following Arjun Appadurai (1990), one may argue that Koti bodyscapes are marked by their historical, linguistic and political situatedness, and have inflected their livelihoods, sexuality, intimate practices and social locations. The alternative bodyscapes embodied by the Kotis subvert hegemonic intimate practices, and succeed at not being tamed or contained within them. However, the lockdown, resulting from the pandemic, violently compromised the existing alternative Koti bodyscapes. The interpersonal relationships of Kotis play a big role in the constitution of their intimate personhoods. However, the pandemic had resulted in the withering away of their livelihoods and their intimate practices. In the last few decades, India has witnessed substantial civil society activism along with judicial and legislative developments in favour of the GVCs. The pandemic has reversed the process and reinscribed hegemonic normativities surrounding intimacy in Indian society by emboldening heteronormative intimate practices at the expense of Koti intimacies. With more and more Kotis and other GVC individuals reinforcing and adhering to gender-normative standards, the assertion of sexual minorities for an alternative societal space might become seriously jeopardised in the near future.

\section{Acknowledgements}

I thank the anonymous referees and the journal editors immensely for their insightful comments. I also thank my supervisor, Johannes Quack, for encouraging me to pursue my passion for research and writing. 
BANHISHIKHA GHOSH is a Swiss Government Excellence PhD Scholar at the Department of Social Anthropology and Cultural Studies (ISEK) at the University of Zurich. Her research is on the intimate practices of gender-variant communities in eastern India. She completed her Master's and MPhil from the Centre for the Study of Social Systems (CSSS/ SSS), Jawaharlal Nehru University in New Delhi. E-mail: banhishikha.ghosh@uzh.ch

\section{Notes}

1. The term "GVCs" is used to refer to a plethora of identities such as Hijra, Kinner, Koti and Kojjas existing in India who do transgress gender norms and participate in cross-dressing.

2. Koti, Kothi and Kojjas refer to effeminate men who cross-dress and live by ritual begging and/or sex work.

3. A hegemonic bodyscape refers to the legitimisation and reinforcement of binary gender representations and the cultivation of normative ideas of bodily presentations across spaces. Although they are never absolute, gender binaries tend to be idealised (Geller 2009).

4. Intimacy in this context is defined as the state of being personally intimate; intimate friendship or acquaintance; familiar intercourse; close familiarity' (Bettcher 2012: 384).

5. All names (except that of Santosh Kr. Giri) have been changed to protect the privacy of my respondents.

6. The terms Hijra and Kinner are used to refer to a popular sexual minority group in South Asia whose members are argued to be a third gender and 'neither man nor woman' (Nanda 1990). However, scholars have documented several variations amongst them and their cultural practices.

7. CBOs are non-profit organisations where a significant segment of a community works together to assert and meet its needs.

8. Kolkata Rista, a CBO, works for people with gendervariant identities, and it has centres across northern and eastern India.

\section{References}

Appadurai, A. (1990), 'Disjuncture and Difference in the Global Culture Economy', Public Culture 2, no. 2: 1-24, doi:10.1177/026327690007002017.

Bettcher, T. (2012), 'Full-Frontal Morality: The Naked Truth about Gender', Hypatia: A Journal of Feminist
Philosophy 27, no. 2: 319-337, doi:10.1111/j.1527-2001 .2011.01184.x

Geller, P. (2009), 'Bodyscapes, Biology, and Heteronormativity,' American Anthropologist 111, no. 4: 504-516, doi:10.1111/j.1548-1433.2009.01159.x.

Jose, D. (2020), 'Transgenders Shocked by Hate Posters in Hyderabad amid Coronavirus Fear', New Indian Express, 30 March, https://www.newindi anexpress.com/cities/hyderabad/2020/mar/30/ transgenders-shocked-by-hate-posters-in-hyder abad-amid-coronavirus-fear-2123284.html.

Maffesoli, M. (1996), The Time of the Tribes: The Decline of Individualism in Mass Society (London: Sage Publications).

Mead, G. H. (1962), Mind, Self, and Society (Chicago: University of Chicago Press).

Misra, P. (2020), 'India Adapting to a Post-COVID-19 World', The Gleaner, 12 July, http://jamaica-gleaner .com/article/focus/20200712/prathit-misra-indiaadapting-post-covid-19-world.

Nanda, S. (1990), 'Neither Man nor Woman': The Hijras of India, 2nd ed. (Belmont, CA: Wadsworth Publishing Company).

Panday, C. (2020), ‘COVID-19: Tripura Transgender Persons Facing Financial Crunch', EastMojo, 24 April, https://www.eastmojo.com/coronavirusupdates/2020/04/24/covid-19-tripura-transgenderpersons-facing-financial-crunch.

Plummer, K. (1995), Telling Sexual Stories: Power, Change and Social Worlds (London: Routledge).

Reddy, G. (2005), With Respect to Sex: Negotiating Hijra Identity in South India (Chicago: University of Chicago Press).

Rosario, K. (2020), 'COVID-19 Lockdown: Transgender Community Pushed Further to the Margin', The Hindu, 6 April, https://www.thehindu.com/news/ cities/mumbai/covid-19-lockdown-transgendercommunity-pushed-further-to-the-margin/article31 265535.ece.

Shaikh, S., G. Mburu, V. Arumugam, N. Mattipalli, A. Aher, S. Mehta and J. Robertson (2016), 'Empowering Communities and Strengthening Systems to Improve Transgender Health: Outcomes from the Pehchan Programme in India', Journal of the International AIDS Society 19, no. 3: doi:10.7448/ IAS.19.3.20809.

Silva, E., and C. Smart, (eds) (1999), The New Family? (London: Sage Publications).

The Week (2020), 'Hate Posters against Transgenders in Hyderabad amid COVID-19 Fears', The Week, 30 March, https://www.theweek.in/news/india/ 2020/03/30/hate-posters-against-transgendersin-hyderabad-amid-covid-19-fears.html. 
Times of India (2020), 'Transgender Who "Fell on Hard Times" Ends Life in Mumbai', Times of India, 12 May, https://timesofindia.indiatimes.com/city/mumbai/ transgender-who-fell-on-hard-times-ends-life-inmumbai/articleshow/75690961.cms.
Trivedi, D. (2020), 'COVID-19 and the Plight of the Transgender Community', Frontline, 29 April, https://frontline.thehindu.com/dispatches/article 31463945.ece\#!. 